\title{
Pain Complaint Threshold in Relation to Pain of Cardiac Infarction
}

\author{
KENNETH D. KEELE,* M.D., F.R.C.P.
}

Brit. med. Y., 1968, 1, 670-673

Though the sensitivity of the patient to noxious stimulation has long been recognized as an important factor in relation to symptom production, its quantitative assessment has received little attention. While it is common for clinicians to express an opinion on the sensitivity of the patient, usually when surprised by an apparent excess or absence of pain, such opinions are almost invariably unsupported by any evidence of the patient's threshold of pain complaint.

That such differences in pain sensitivity as expressed by the threshold of pain complaint can be quantitated meaningfully in relation to the pain of cardiac infarction is the theme of this paper.

\section{Threshold of Pain Complaint}

This term is used to describe the relation between the quantitative application of a stimulus to a patient and his first complaint of pain. Such a stimulus was first used by Libman (1934), who observed the patient's response to the application of pressure to the styloid process of the mastoid. Though the stimulus used was only crudely quantitated, Libman found his test useful for separating patients into normal and hyposensitive groups; and he concluded that important variations in clinical syndromes were found in hyposensitive patients.

More accurate quantitation of the pressure pain stimulus was necessary to clarify the value of such a procedure. In 1954 the technique and results of such "pain sensitivity tests" with the pressure algometer were reported (Keele, 1954), with observations on their consistency in the same individual on different occasions. This correlated closely with other methods of estimating pain sensitivity; of particular interest was its close relation with forearm ischaemic pain, as described by Lewis (1942). Consistent results for pressure pain sited on the forehead gave a normal range of between 0.5 and $6 \mathrm{~kg}$. In $23 \%$ of subjects the threshold was less than $2 \mathrm{~kg}$.; these were called " hypersensitives." In the $62 \%$ " normosensitive" persons it ranged between 2 and $4 \mathrm{~kg}$. The remaining $15 \%$ of persons were "hyposensitive" with thresholds above this.

The "reliability" of this pressure algometer test was investigated by Merskey and Spear (1964), using the term "verbal report of pain" instead of "pain threshold." They report "good correlation between different observers, occasions, and sites" for the method. Expressed as coefficients of variation the verbal report of pain varied from 22 to $33 \%$. They conclude : "We think, therefore, that pressure pain has a degree of reliability which makes possible its quantitative use for investigations of emotional states, anaesthesia, and analgesia."

Since the vigorous controversy regarding the interpretation of the term "pain threshold," in which Hardy and Beecher have been engaged during the past 15 years, loaded this term with too crushing a semantic burden, it is necessary to use other terms such as "verbal report of pain" or "threshold of pain complaint." These make it quite clear that one is dealing with the patient's statement or complaint of pain, and no other phenomenon.

\section{Cardiac Infarction in the Hyposensitive Patient}

When it became clear that there was a group of persons who made no complaint of pain with pressure stimuli of 4 to 6 or more kg., and with forearm ischaemia complained of fatigum rather than pain, the question arose whether such persons com plained of pain when stimulated by "painful " disease pro. cesses. How, if at all, was this hyposensitivity as regards com plaint of pressure pain associated with the syndromes of " pain ful" diseases ? For example, how, if at all, did it appear tc modify the syndrome of cardiac infarction? The observatior of the following case of cardiac infarction suggested that the noxious stimulation of this event was profoundly modified it its expression as a syndrome by gross hyposensitivity of th. patient.

A man aged 68 attended the outpatient clinic complaining of dyspnoea only, without pain. Examination showed a pulsu, alternans. Electrocardiogram showed recent anterior infarctior Recovery was uneventful. He could walk 6 miles $(10 \mathrm{~km}$.) witk no angina of effort. He remained well for 17 months, when the dyspnoea returned, once more without pain. On admission he wa, found to have electrocardiographic evidence of extension of antero. septal infarction, from which he died. Post-mortem appearance, (see Fig.) confirmed the diagnosis. This patient was grossly hypo. sensitive to the stimulus of the pressure algometer, not complainin of pain at $6 \mathrm{~kg}$. (a stimulus beyond which one does not go for fear of producing tissue damage).

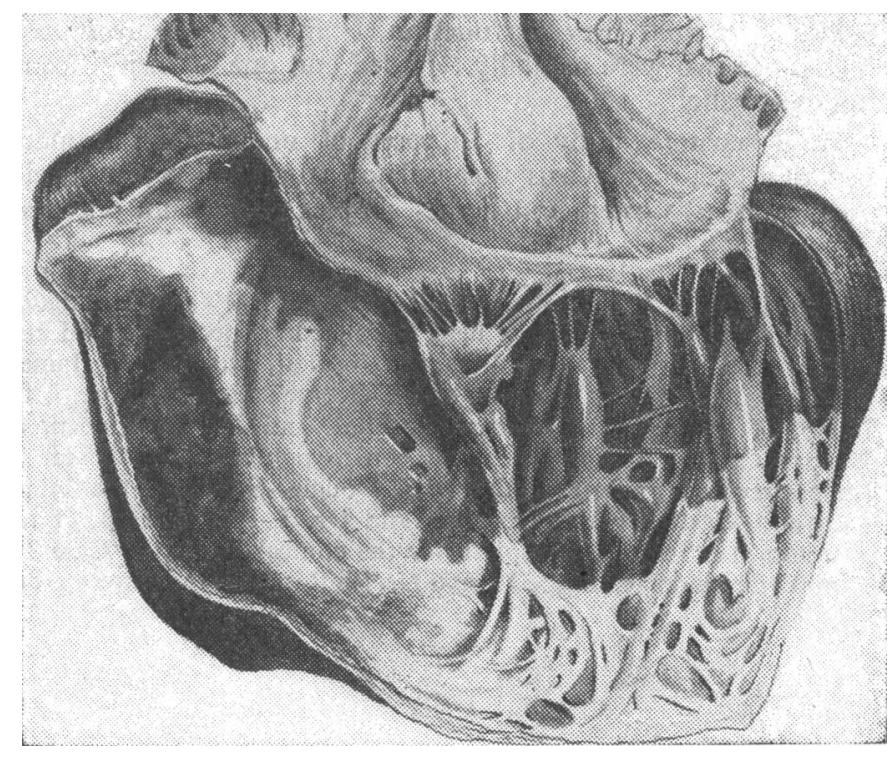

Old anterior infarction involving lower two-thirds of septum. Overlying this is an area of recent necrosis covered by thrombus.

This and similar observations gave the clinical impression that pain experienced with cardiac infarction bore an inverse relation to the threshold of complaint of the patient to pressure pain. Moreover, patients with low thresholds to pressure pair seemed to experience much pain regardless of the size of th. infarct.

\section{Magnitude of Noxious Stimulation in Infarction}

The possible relation between the extent of the infarction and the pain pattern was clearly a relevant aspect of the syndrome of cardiac infarction. This presented the problem of 
assessing the size of the cardiac infarct in any given case. It so happens that in cardiac infarction there are two features which can be approximately correlated with the magnitude of the infarct, and so with the magnitude of the noxious stimulation. These are the liberation of intracellular enzymes-for example, the aspartate aminotransferase (S.G.O.T.) and alanine aminotransferase (S.G.P.T.) - and the extent of electrocardiographic changes.

It is agreed that in cardiac infarction the noxious stimulus consists of the products of muscle ischaemia resulting from anoxia and necrosis. These processes liberate intracellular painproducing substances into the extracellular tissues, among which are the potassium ion, 5-hydroxytryptamine, plasma kinins, and proteins. As a quantitative index of these one may observe the appearance of the intracellular transaminases as estimated in the plasma. The peak value of the S.G.O.T., usually at 36 hours, was therefore taken as a measure of both the rate and magnitude of the chemical aspect of the noxious stimulus of cardiac infarction. The S.G.P.T., being more sensitive to hepatic dysfunction, was synchronously measured as a control to exclude relevant renal or hepatic damage from ischaemia or congestion as a possible cause of the rise of the S.G.O.T. Both enzymes were measured daily for five days after the onset of infarction, the peak value during that period being taken as an index of the production of pain-producing substances from the myocardial infarction-that is, the noxious stimulus.

The extent of myocardial infarction is also, reflected in the spatial distribution of electrocardiographic changes, as shown by the number of leads in the standard 12-lead electrocardiogram showing significant changes. In this series standard 12lead electrocardiograms were taken on admission, 12 hours later, and each subsequent 24 hours for five days. The extent of infarction was assessed from the number of leads in which diagnostic $Q$ waves or $S-T$ segment elevation or depression of more than $1 \mathrm{mV}$ were found, and $\mathrm{T}$-wave inversion. This was taken as an independent index of the magnitude of the noxious stimulus. It ' was correlated with the peak serum transaminase level in each case, previous observations having shown significant correlation between the extent of electrocardiographic changes and the S.G.O.T. (Keele, Goulden, and Newman, 1958).

In a series of 74 patients admitted with cardiac infarction a relation was sought between: (1) the pressure pain complaint threshold; (2) features of the pain syndrome such as severity, extent, duration, and analgesic requirement ; (3) the magnitude of the infarction as estimated by $(a)$ peak S.G.O.T. values and S.G.P.T. values and $(b)$ the number of leads showing specific changes of anoxia or necrosis in the standard 12-lead electrocardiogram.

For the statistical analysis of the combined data sets for the results in 74 subjects I am greatly indebted to $\mathrm{Mr}$. Gerald J. Knight, of the Statistics Section at the Medical Research Department of the Wellcome Research Laboratories.

\section{Pain Complaint Threshold and Intensity of Pain}

The intensity of pain was divided into four categories: (1) "slight," (2) " moderate," (3) " severe," and (4) " agonizing." Slight was described as pain insufficient to interrupt normal activities. Moderate pain demanded notice, something being done to relieve it. Severe pain usurped the field of consciousness to the exclusion of other events, including such activities as eating and drinking, etc., with urgent search for relief. Agonizing pain gave rise to kinetic disorganization, the patient rolling on the floor, beating his chest, groaning, etc. These grades of pain were found meaningful when explained to the patients.

A significant inverse relation was found between the pain complaint threshold and the severity of pain thus graded
$(0.05>P>0.01)$. It is noticeable that there was no difference in the pain complaint threshold of those complaining of "slight" and those complaining of "moderate" pain; thus these distinctions in terms in fact bore no significantly different meaning; the others did (Table I).

TABLE I.-Pain Complaint Threshold and Severity of Pain

\begin{tabular}{|c|c|c|c|c|c|}
\hline & & \multicolumn{4}{|c|}{ Pain Severity } \\
\hline & & 1 & 2 & 3 & 4 \\
\hline $\begin{array}{l}\text { No. of subjects in category } \\
\text { Mean pain threshold }\end{array}$ & $\ddot{n}$ & $\begin{array}{c}6 \\
3.67\end{array}$ & $\begin{array}{c}18 \\
3 \cdot 67\end{array}$ & $\begin{array}{c}36 \\
3 \cdot 04\end{array}$ & $\begin{array}{r}14 \\
2 \cdot 21\end{array}$ \\
\hline
\end{tabular}

Difference
significant.

Increasing intensity of severity of pain was, as expected, associated with increasing spread of pain over larger areas of the body. For this purpose the areas denoted were: front of chest, left upper arm, left lower arm, right upper arm, right lower arm, jaws, and back (Table II) $(0.01>P>0.001)$. The pain complaint threshold was also inversely related to the area involved, but this difference was not statistically significani $(\mathrm{P}>0.10)$.

TABLE II.-Pain Severity and Areas of Pain

\begin{tabular}{|c|c|c|c|c|}
\hline & & \multicolumn{2}{|c|}{ Pain Severity } & \multirow{2}{*}{ Total } \\
\hline & & $\leqslant 2$ & $>2$ & \\
\hline Pain areas $\left\{\begin{array}{l}1,2, \text { or } 3 \\
4,5, \text { or } 6\end{array} \ldots\right.$ & 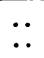 & $\begin{array}{r}20 \\
4\end{array}$ & $\begin{array}{l}25 \\
25\end{array}$ & $\begin{array}{l}45 \\
29\end{array}$ \\
\hline Total & .. & 24 & 50 & 74 \\
\hline
\end{tabular}

Case histories illustrate the relevance of these factors:

A man aged 52, whose pain complaint threshold was $6.0 \mathrm{~kg}$., had a posterior cardiac infarction, with S.G.O.T. of 176 units and S.G.P.T. of 19 units. The E.C.G. showed S-T segment elevation in six leads. The pain experienced was described as moderate; it was located in the substernal region and in both upper arms; it lasted for approximately 15 hours. During it he neither asked for nor received any analgesic.

In contrast, a man aged 69 , whose pain complaint threshold was $0.5 \mathrm{~kg}$., had an anterior infarction, raising the S.G.O.T. to 52 units and the S.G.P.T. to 13 units. The E.C.G. showed S-T segment elevation in three leads out of the 12. The pain experienced was described as agonizing, the patient being found rolling on the floor. It extended over the chest and down both arms to the hands, lasted 48 hours, and required morphine $15 \mathrm{mg}$. and pethidine $50 \mathrm{mg}$. on three occasions for relief.

\section{Pain Complaint Threshold and Duration of Pain}

The measurement of the duration of the pain of cardiac infarction is not as easy as might be expected. Though the time of onset can be fairly accurately recorded, its cessation is usually ill defined, often with a wide margin of some hours. Sometimes this is due to the period of vague uneasiness or "discomfort" which follows the pain, and the effect of analgesic drugs, particularly morphine. If the patient falls asleep and wakes free from pain the timing of the end of pain is impossible. The degree to which amnesia after morphine can obscure the end-point of pain was illustrated by a patient seen one evening in agonizing pain, writhing in bed in a state well described by the phrase "complete kinetic disorganization." He was given morphine $15 \mathrm{mg}$., after which he went to sleep. In the morning, some 14 hours later, to an inquiry about his pain he replied, "What pain ?" He had completely forgotten the episode. Such complete amnesia is not common, but lesser degrees of it are, and illustrate the difficulty of timing the duration of pain. For this reason the duration of pain in these patients was expressed as categories rather than as continuous quantities; each category consisting of six-hourly periods up 
to 72 hours. Beyond this duration there were usually complicating or recurrent episodes. Table III shows a significant inverse relation between the duration of pain and pain complaint threshold ; the longer the duration the lower the threshold $(0.05>\mathrm{P}>0.01)$.

TABLB III.-Pain Complaint Threshold and Pain Duration

\begin{tabular}{|c|c|c|c|c|c|c|}
\hline & & \multicolumn{5}{|c|}{ Duration (Hours) of Pain (Categories) } \\
\hline & & $<6$ & $6-12$ & $13-24$ & $25-72$ & $>72$ \\
\hline $\begin{array}{l}\text { No. of subiects in category } \\
\text { Mean pain threshold }\end{array}$ & $\because$. & $\begin{array}{c}15 \\
3.83\end{array}$ & $\begin{array}{c}19 \\
3 \cdot 21\end{array}$ & $\begin{array}{c}16 \\
3 \cdot 28\end{array}$ & $\begin{array}{c}12 \\
2 \cdot 42\end{array}$ & $\begin{array}{c}12 \\
2 \cdot 37\end{array}$ \\
\hline
\end{tabular}
ignificant.

The following cases illustrate this relation:

A man aged 42, with pain complaint threshold of $1 \mathrm{~kg}$, had an anterior infarction raising the S.G.O.T. to 62 units and S.G.P.T. to 22 units. The E.C.G. showed S-T changes in four leads. Pain spread over front and back of chest, down both arms to the hands, and into the jaw ; it was very severe and lasted some 120 hours. This pattern is similar to that of the patient aged 69 cited above.

In contrast, a man aged 61 , with pain complaint threshold $5.0 \mathrm{~kg}$., had an anterior infarction raising the S.G.O.T. to 110 units and the S.G.P.T. to 21 units, with E.C.G. changes in S-T segment in one lead. He experienced moderate pain substernally and in both upper arms for two hours. No analgesic was given.

\section{Morphine Sulphate Dosage in Relation to Pain Complaint Threshold}

As laid out in Table IV, the morphine requirement of these patients was divided into four categories: none, one dose, two doses, or more than two doses. In all cases the individual dose was standardized at $15 \mathrm{mg}$. ( $1 \mathrm{gr}$.). Repetition of the injection was made at the decision of the doctor in charge. On the diagnosis of myocardial infarction most patients received an injection of morphine; in some cases these may have been unnecessary. Apart from this, severe or moderate pain or distress was taken as an indication for morphine administration. Pethidine was used for pain or distress of slighter degree.

TABLE IV.-Pain Complaint Threshold and Morphine Dose

\begin{tabular}{|c|c|c|c|c|c|}
\hline & \multicolumn{4}{|c|}{ No. of Doses } \\
\hline & & 0 & 1 & 2 & $>2$ \\
\hline $\begin{array}{l}\text { No. of subiects in category } \\
\text { Mean pain threshold } \quad \text {.. }\end{array}$ & 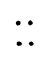 & $\begin{array}{c}27 \\
3 \cdot 44\end{array}$ & $\begin{array}{c}16 \\
2 \cdot 78\end{array}$ & $\begin{array}{c}16 \\
3 \cdot 47\end{array}$ & $\begin{array}{c}15 \\
2 \cdot 37\end{array}$ \\
\hline
\end{tabular}
significant.

Table IV shows the distribution of cases categorized according to the number of doses of morphine and the pain complaint threshold. Significantly less morphine is required in those patients with the higher threshold $(0.05>P>0.01)$. This agrees with the observation above, that the lower the threshold of complaint the longer was the duration of pain-such patients requiring more morphine. Conversely, hyposensitivity with a high threshold of pain complaint was associated with a morphine-sparing effect, which is expressed in three ways: through diminished severity or intensity of pain (Table I) ; through diminished area of pain (Table II); and through shorter duration of pain (Table III).

The influence of the pain complaint threshold on the duration rather than intensity of pain is illustrated by two cases. (1) A man with a pain complaint threshold of $4 \mathrm{~kg}$. had an extensive infarct with S.G.O.T. 130 units. He experienced severe pain lasting seven hours, requiring one dose of morphine (15 mg.) for relief. (2) A man with a pain complaint threshold of $1 \mathrm{~kg}$. had a small infarct with S.G.O.T. of 62 units. He experienced severe pain lasting for five days, requiring eight injections of morphine (15 mg.) for relief.
In Table $\mathrm{V}$ pain duration and the number of doses of morphine are laid out so that the point of dichotomy was determined by the median of pain durations. It shows the highly significant inverse relation between the duration of pain and the required number of doses of morphine $(P<0.001)$.

\begin{tabular}{|c|c|c|c|c|}
\hline \multirow{2}{*}{\multicolumn{2}{|c|}{ Morphine Doses }} & \multicolumn{2}{|c|}{ Pain Duration (Hours) } & \multirow{3}{*}{$\begin{array}{c}\text { Total } \\
43 \\
31 \\
\end{array}$} \\
\hline & & \multirow{2}{*}{$\begin{array}{c}\leqslant 18 \\
30 \\
9\end{array}$} & \multirow{2}{*}{$\begin{array}{c}>18 \\
13 \\
22\end{array}$} & \\
\hline $\begin{array}{l}<1 \\
>1\end{array}$ & 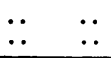 & & & \\
\hline & .. & 39 & 35 & 74 \\
\hline
\end{tabular}

\section{Cases not Requiring Morphine}

Of the 74 cases 27 did not require morphine; some of these, however, received analgesics by mouth. It was noted that the absence of need for morphine was not always the result of a short duration of pain but sometimes of its moderate intensity only. For example, a man aged 52, with a pain complaint threshold of $6 \mathrm{~kg}$., recorded pain of moderate intensity substernally, radiating down both arms to the hands for 15 hours. This came on while he was watching a football match; it did not prevent him from enjoying the rest of the match, nor from walking home with his son. His cheerful manner was such that he neither asked for nor received any analgesic treatment at all ; yet his S.G.O.T. rose to 176 units and there were S-T segment changes in six leads.

In a representative sample of the patients not requiring morphine the size of the infarctions as reflected by the S.G.O.T. were $34,36,50,57,68,75,87,95,128$, and 176 units. The respective pain complaint thresholds of these patients were $3,3.5,3.5,2,4,3.5,3.5,5.5,4.5$, and $6 \mathrm{~kg}$. From this series it will be seen that the higher the threshold of pain complaint the larger the infarction which was borne without requiring morphine. If a patient has a threshold of about $6 \mathrm{~kg}$., however large his infarct, he often does not need morphine. Such a patient has recently been seen with a pain complaint threshold of $6+\mathrm{kg}$.: a man of 81 with antero-lateral-posterior infarction on the E.C.G., and S.G.O.T. of 360 units, whose substernal and left upper arm pain lasted three hours. Because of a diagnosis of "doubtful" cardiac infarction and short duration of pain he was given no analgesic at all.

\section{Morphine Requirement and Size of Infarct}

The size of the infarct was assessed from the number of leads in the E.C.G. showing pathological $Q$ waves, S-T segment deviation, and $T$-wave inversion. Of these, significant association was found between the $S-T$ segment changes and the requirement of morphine, as shown in Table VI

TaBle VI.-S-T Segments and Morphine Dose

\begin{tabular}{|c|c|c|c|}
\hline \multirow{2}{*}{ Morphine Doses } & \multicolumn{2}{|c|}{ S-T Segments (No. of Leads) } & \multirow{2}{*}{ Total } \\
\hline & $\leqslant 4$ & $>4$ & \\
\hline $\begin{array}{l}\leq 1 \\
>1\end{array}$ & $\begin{array}{l}25 \\
10\end{array}$ & $\begin{array}{l}18 \\
21\end{array}$ & $\begin{array}{l}43 \\
31 \\
\end{array}$ \\
\hline Total & 35 & 39 & 74 \\
\hline
\end{tabular}

$(0.05>P>0.02)$, where $S-T$ segment deviation occurring in more than four leads is significantly associated with the number of doses of morphine required. Similar association was found between the S.G.O.T. level and morphine dosage $(0.05>\mathrm{P}>0.02)$.

In the case of pathological $Q$ waves, though the trend was similar, it did not reach statistical significance $(P>0.10)$. The 
most highly significant correlation lay between morphine requirement and the number of leads showing $T$-wave changes (Table VII) $(\mathrm{P}<0.001)$.

\begin{tabular}{|c|c|c|c|}
\hline \multirow{2}{*}{ Morphine Doses } & \multicolumn{2}{|c|}{ No. of Leads with $T$-Wave Changes } & \multirow{2}{*}{ Total } \\
\hline & $\leqslant 5$ & $>5$ & \\
\hline $\begin{array}{l}<1 \\
>1\end{array}$ & $\begin{array}{l}34 \\
12\end{array}$ & $\begin{array}{r}9 \\
19\end{array}$ & $\begin{array}{l}43 \\
31\end{array}$ \\
\hline Total & 46 & 28 & 74 \\
\hline
\end{tabular}

Thus the morphine requirement was significantly related inversely to the pain complaint threshold of the patient and directly to the magnitude of the cardiac infarction, as estimated by these criteria.

\section{Consistency of Methods}

With regard to these two methods of estimating the magnitude of infarction it was noted that the S.G.O.T. peaks were highly significantly related to the number of leads showing S-T segment deviation (Table VIII) $(P<0.001)$ and to the extent of pathological $Q$ waves (Table IX) $(0.01>P>0.001)$. The S.G.P.T., used primarily for excluding hepatic and other noncardiac causes of elevation of the S.G.O.T., nevertheless showed significant relation to the extent of $S-T$ segment deviation $(0.05>P>0.02)$ as well as to the S.G.O.T. There was thus close internal consistency between the electrocardiographic and the transaminase estimates of the magnitude of the noxious stimulus of cardiac infarction.

TABlB VIII. $-S-T$ Segment Changes and S.G.O.T.

\begin{tabular}{|c|c|c|}
\hline & \multicolumn{2}{|c|}{ S-T Segment (No. of Leads) } \\
\hline & $\leqslant 4$ & $>4$ \\
\hline $\begin{array}{l}\text { No. of subjects in category ... } \\
\text { Mean S.G.O.T. } \quad . . \quad \text {. }\end{array}$ & $\begin{array}{c}35 \\
65.6571\end{array}$ & $122 \cdot 8205$ \\
\hline \multicolumn{3}{|c|}{ Difference between means ( $t$ test: $t=4.2609)(\mathrm{P}<0.001)$ highly significant } \\
\hline & \multicolumn{2}{|c|}{ Q Waves (No. of Leads) } \\
\hline & $\leqslant 1$ & $>1$ \\
\hline $\begin{array}{l}\text { No. of subjects in category ... } \\
\text { Mean S.G.O.T. }\end{array}$ & $\begin{array}{c}35 \\
72 \cdot 1142\end{array}$ & $115 \cdot 7435$ \\
\hline
\end{tabular}

Difference between means ( $t$ test: $t=3.0527)(0.01>P>0.001)$ very significant.

\section{Conclusion}

In these 74 patients with cardiac infarction the pain pattern of the syndrome correlated with two factors: (1) directly with the magnitude of the noxious stimulus of cardiac infarction as assessed by the peak of the S.G.O.T. changes and the extent over which electrocardiographic changes were found; and (2) inversely with the patient's threshold of pain complaint as assessed with the pressure algometer. This threshold is inversely related to the intensity of pain experience, its spread, its duration, and the requirement of morphine.

Large cardiac infarctions in hyposensitive patients with pressure pain complaint thresholds above $4 \mathrm{~kg}$. have produced relatively little pain as estimated by its intensity, spatiotemporal dimensions, and morphine requirement.

For a given size of cardiac infarction the hypersensitive patient has complained of pain which has been more intense, more widespread, and of longer duration than that of the hyposensitive patient. This relationship was shown to be significant, and was valid only when the pain complaint threshold was taken into account. Pain " severity" or intensity was only one of several features of the pain pattern which correlated directly with the magnitude of the noxious stimulus, and inversely with the pain complaint threshold.

Hyposensitivity has been found related to the behaviour of the patient-for example, it is reflected in his taking action to call in the doctor. Two hyposensitive patients with large cardiac infarcts but only moderate pain would not have called the doctor at all if it had not been for the concern of their wives. This group of persons probably provides a pool of what may be called occult cardiac infarctions, using this term to include undiagnosed, perhaps undiagnosable, cases, since not seen. It is possible, too, that some cases are truly asymptomatic.

In many patients with cardiac infarction a knowledge of both the pain complaint threshold and the pain pattern can be translated into a useful estimate of the transaminase levels and the extent of the electrocardiographic changes.

\section{Summary}

The use of experimental pain in relation to the assessment of clinical pain has been but little explored. Here such an approach has been made by producing a miniature pain "dis-ease" by the stimulus of pressure pain, from which the patient's complaint threshold was obtained. This has been compared with the pain pattern of cardiac infarction in the patient.

Experimentally, the pressure pain complaint threshold is consistent in individuals. In different persons it ranges for this technique between 0.5 and $6.0 \mathrm{~kg}$. Moreover, the pressure pain complaint threshold varies along with that of experimentally produced forearm ischaemic pain in the same person.

Clinically, patients with high pressure pain complaint thresholds were observed to complain little of cardiac pain with cardiac infarction, and conversely.

Statistically, in 74 patients a correlation was therefore sought between: (1) pressure pain complaint threshold; (2) features of the pain syndrome of cardiac infarction-for example, severity, extent, duration, and morphine requirement ; $(3)$ the magnitude or intensity of the noxious stimulus as estimated from two independent criteria, peak S.G.O.T. levels, and the number of leads in the standard 12-lead electrocardiogram showing changes.

The severity, extent, and duration of the pain, and the morphine requirement, were all found to be diminished with elevation of the patient's pressure pain complaint threshold. These same features of the pain pattern increased in proportion to the intensity of the noxious stimulus as estimated from the peak S.G.O.T. and E.C.G. changes.

The pain pattern in a case of cardiac infarction is a function of both the pain complaint threshold and the noxious stimulation. A high pain complaint threshold constitutes an important factor in the incidence of undiagnosed relatively painless cases of cardiac infarction.

\section{REFERENCES}

Keele, K. D. (1954). Lancet, 1, 636.

Keele, K. D., Goulden, F., and Newman, M. J. D. (1958). Lancet, 2, 1187.

Lewis, T. (1942). Pain, p. 97. New York.

Libman, E. (1934). f. Amer. med. Ass., 102, 335

Merskey, H., and Spear, F. G. (1964). Brit. F. soc. clin. Psychol., 3, 130. 